\title{
Radiocarbon Analysis of Carbonaceous Aerosols: Recent Developments
}

\author{
Sönke Szidat*
}

\begin{abstract}
Carbonaceous aerosols are a major fraction of airborne particulate matter. They contribute to climate and health effects of the total aerosol burden of the atmosphere by counteracting the current trend of global warming and inducing respiratory and cardiovascular diseases, respectively. In spite of this general importance, only little is known about composition and sources of carbonaceous aerosols. Analysis of the long-lived radioactive isotope ${ }^{14} \mathrm{C}$ (radiocarbon) is a unique source apportionment tool: it unambiguously separates fossil from non-fossil sources, as ${ }^{14} \mathrm{C}$ has completely decayed in fossil fuels, whereas modern materials have the contemporary radiocarbon level. A novel separation method was developed for the direct determination of ${ }^{14} \mathrm{C}$ in organic carbon (OC) and elemental carbon (EC), two sub-fractions of total carbon (TC). The implementation of a gas ion source for measurement with accelerator mass spectrometry (AMS) made ${ }^{14} \mathrm{C}$ analysis more simple and robust. Based on this technique, all major contributions to the carbonaceous aerosol can be identified, which originate from fossil-fuel, biomass-burning and biogenic emissions. A survey of results from different field campaigns is shown.
\end{abstract}

Keywords: Analytical development · Carbonaceous aerosols · Environmental particulate matter · Radiocarbon analysis · Source apportionment

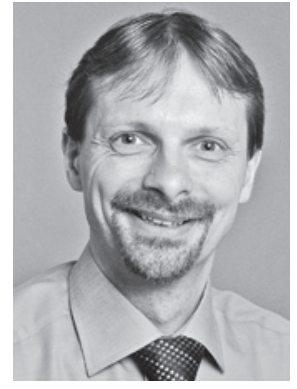

Sönke Szidat was born in 1970 and studied chemistry in Hannover with focus on analytics. His obtained his $\mathrm{PhD}$ under the direction of Prof. Rolf Michel for environmental studies on the long-lived radioisotope iodine-129. Afterwards, he started his postdoctoral research at the Department of Chemistry and Biochemistry of University of Bern, where he acquired a group head position in 2007 Sönke Szidat was awarded the Promotionspreis by the Nuclear Chemistry Division of the German Chemical Society (GDCh) and the ACP Prize by the Atmospheric Chemistry and Physics Commission of the Swiss Academy of Sciences (SCNAT).

\footnotetext{
${ }^{*}$ Correspondence: Dr. S. Szidat

University of Bern

Department of Chemistry and Biochemistry

Freiestrasse 3

$\mathrm{CH}-3012$ Bern

Tel.: +41316314308

Fax: + 41316314220

E-mail: szidat@iac.unibe.ch
}

\section{Introduction}

Suspensions of liquid or solid particles in a gas are generally denoted as aerosols. In atmospheric sciences, the term aerosol characterizes suspended particles in air containing a large proportion of condensed matter. ${ }^{[1,2]}$ The size of these particles range from a few nanometers for small molecular clusters to $>100 \mu \mathrm{m}$. Concerning the process of formation in the atmosphere, particulate matter is classified into primary aerosol, which is directly emitted as particles, and secondary aerosol, which is generated by atmospheric oxidation from gaseous precursors. During the latter process, less volatile compounds are formed, which then may partition into the aerosol phase. Concentration, size-distribution, and composition of ambient particulate matter may vary largely as a consequence of spatial and temporal differences of formation, atmospheric transformation, transport and deposition of aerosols.

Natural and anthropogenic aerosols have a strong impact on climate ${ }^{[3]}$ and human health. ${ }^{[4]}$ The global climate is influenced by particulate matter due to changes of the radiative forcing, i.e. energy fluxes of solar and terrestrial radiation. Among all radiative forcings, the impact of aerosols is the most relevant cooling effect, which roughly halves the global warming trend of greenhouse-gas and ozone emissions for current estimations. ${ }^{[3]}$ Health effects of particulate matter are attributed to short-term exposure (e.g. acute symptoms like wheezing, coughing, phlegm production, and respiratory infections) and long-term exposure (e.g. chronic respiratory or cardiovascular disease, intrauterine growth restriction, lung cancer), which may even induce enhanced mortality. Based on an evaluation of many epidemiologic studies, $\mathrm{WHO}^{[4]}$ defined $20 \mu \mathrm{g} \mathrm{m}^{-3}$ for PM10 (i.e. particulate matter with an aerodynamic diameter $<10 \mu \mathrm{m}$ ) as the air quality guideline for protection of public health, a level for which increased mortality in response of long-term exposure has already been observed. $\mathrm{WHO}^{[4]}$ concluded further that exceeding the air quality guideline by $10 \mu \mathrm{g} \mathrm{m}^{-3}$ results in enhanced all-cause death incidents of 3\%. For Switzerland, 3700 fatalities per year caused by particulate matter inhalation were estimated, ${ }^{[5]}$ mainly as cardiovascular and respiratory responses to long-term exposure.

Carbonaceous aerosol components account for a large fraction of air particulate matter. ${ }^{[2,6]}$ They may contain a huge variety of organic compounds, polymeric and light-absorptive refractory carbon, or carbonate mineral dust, whereof the latter is negligible for many applications in midlatitudes. Traditionally, the total burden of organic carbonaceous particulate matter is denoted as total carbon (TC) and classified into elemental carbon (EC) and organic carbon (OC). Incomplete combustion of solid, liquid, or gaseous fuels produces complex three-dimensional organic polymers with graphitic structures. Due to its properties, this fraction of TC is designated as EC based on the high chemical refractiveness or as black carbon (BC) as a consequence of the strong optical absorption. ${ }^{[2,6]}$ Sources can generally be subdivided into combustion of biomass burning (land clearance, waste burning, residential heating and cooking) 
and fossil-fuel combustion (traffic emissions, mainly from diesel engines, and coal heating). OC comprises organic compounds of low to medium molecular weight, which are non-volatile enough to partition into the aerosol phase. ${ }^{[2,6]}$ Sources of OC have to be considered separately for primary and secondary organic aerosols (POA and SOA, respectively). POA sources include biogenic, wood-burning, fossil-fuel-combustion, anthropogenic non-combustion, soil-resuspension, and sea-spray emissions. SOA is formed from biogenic, fossil, and biomassburning-related precursor gases. ${ }^{[7,8]}$

A large discrepancy exists between atmospheric importance of carbonaceous particulate matter and knowledge of their formation, transformation, and removal. ${ }^{[8-11]}$ Here, radiocarbon $\left({ }^{14} \mathrm{C}\right)$ analysis of carbonaceous aerosols is an important and powerful tool. ${ }^{[12,13]}$ As shown in Fig. $1,{ }^{14} \mathrm{C}$ is used for source apportionment of carbonaceous aerosols due to the contrasting ${ }^{14} \mathrm{C}$ values of modern and fossil materials. As consequence of their age, ${ }^{14} \mathrm{C}$ has completely disintegrated in fossil substances, whereas modern material is at the contemporary radiocarbon level. Due to the different emission sources, ${ }^{[14]}$ it is necessary to chemically separate OC and EC and to analyze ${ }^{14} \mathrm{C}$ in both fractions. ${ }^{[13,15]}$ This work presents the development of techniques for this chemical separation at University of Bern and the ${ }^{14} \mathrm{C}$ determination in the isolated carbonaceous particle fractions at the Laboratory of Ion Beam Physics of ETH Zürich. Furthermore, applications of these methods to aerosol samples from several sites in collaboration with the Laboratory of Atmospheric Chemistry of PSI are briefly summarized.

\section{Experimental}

\subsection{General Requirements}

For a long time, aerosol samples were prepared for ${ }^{14} \mathrm{C}$ measurement exclusively by total combustion of air filters, ${ }^{[12,16,17]}$ as this is, in general, a preferential technique for ${ }^{14} \mathrm{C}$ analysis due to its simplicity. At the start of the work in the laboratory at University of Bern, the idea of source apportionment of carbonaceous aerosols differentiated into OC and EC made necessary several analytical and technical developments:

- Separation of OC and EC with high yields and negligible interferences with the other fraction;

- Construction of a closed system with small volume, which combines combustion of filters at ambient pressure and carbon dioxide collection at high vacuum;

- Transformation of the produced $\mathrm{CO}_{2}$ into a chemical form which allows ${ }^{14} \mathrm{C}$ measurement;

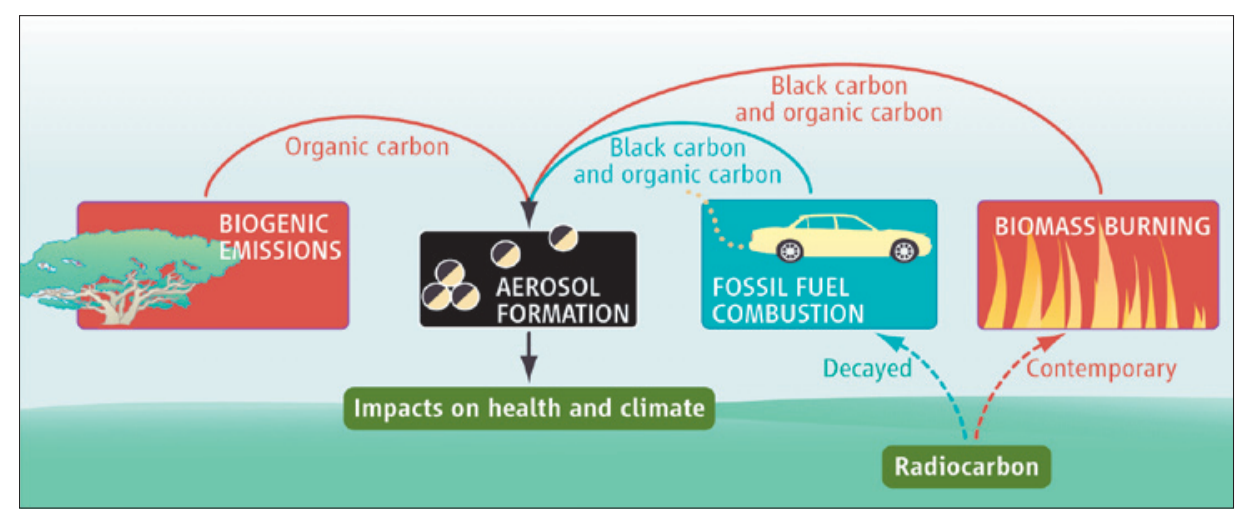

Fig. 1. Source apportionment: Radiocarbon analysis allows fossil and non-fossil sources of BC (equivalent to EC) and $\mathrm{OC}$ to be identified. ${ }^{[13]}$

- Improvement of accelerator mass spectrometry (AMS) measurement protocols in order to scale down applicable sample sizes from milligram amounts of carbon by two orders of magnitude.

Sections 2.2 and 2.3 describe how these requirements were met for the sample preparation of aerosol filters and ${ }^{14} \mathrm{C}$ measurement.

\subsection{Analytical Methods}

The idea of the classification of TC into OC and EC suffers from a lack of clear distinction between the two fractions. [2] With increasing molecular weight and functionality, OC compounds become more and more chemically refractory and optically absorptive, which complicates the chemical separation from EC necessary for ${ }^{14} \mathrm{C}$ measurement. Negative and positive artifacts may occur during analysis of the quartz fiber filters, which have to be minimized. ${ }^{[10]}$ Negative artifacts denote losses in the pretreatment step. As the more refractory part of $\mathrm{OC}$ and the more reactive part of EC can hardly be separated, this intermediate fraction can be ignored under the assumption that the analyzed and the lost part carry the same isotopic signal.[18] Positive artifacts specify an incomplete isolation of one fraction from the other. Here, the partial pyrolytic conversion of $\mathrm{OC}$ during the isolation of EC (often characterized as 'charring') is the most serious problem, because OC is typically 3 to 10 times more abundant than $\mathrm{EC}$ and the ${ }^{14} \mathrm{C}$ values of both fractions can differ widely. ${ }^{[2,14]}$ Consequently, isolation of $\mathrm{OC}$ and $\mathrm{EC}$ for ${ }^{14} \mathrm{C}$ determination aims at a complete removal of the interfering fraction with the best possible recovery.

Traditionally, two different separation strategies have been employed for the determination of concentrations of $\mathrm{OC}$ and EC using controlled temperature programs, which may be in principle adapted to ${ }^{14} \mathrm{C}$ analysis: the evaporation of OC in helium followed by oxidation of EC in a mixture of helium and oxygen ${ }^{[6,19]}$ and the two-step oxidation of $\mathrm{OC}$ and EC in pure oxygen. ${ }^{[20,21]}$ Although the helium-based method is wide- ly applied for the determination of $\mathrm{OC}$ and EC concentrations, it is inappropriate for the isolation of both fractions for ${ }^{14} \mathrm{C}$ analysis, as this technique substantially produces charring during the evaporation of $\mathrm{OC}$ in helium. For the determination of $\mathrm{OC}$ and EC concentrations, an optical on-line monitoring is used to correct for this artifact. ${ }^{[6]}$ For the isolation of both fractions for ${ }^{14} \mathrm{C}$ analysis, however, such corrections cannot be used. ${ }^{[22]}$ Therefore, the two-step oxidation of OC and EC in pure oxygen is the method of choice, as it is much less prone to charring. ${ }^{[20,22]}$ Further reduction of charring for the isolation of EC is achieved by water extraction of the filters prior to the thermal treatment. $[10,14,22]$ This allows the removal of water-soluble inorganic and organic compounds from the filters, which support the artificial production of EC from OC during analysis, whereas EC remains completely on the filter.

Therefore, the two-step heating system for the EC/OC determination of radiocarbon in the environment (THEODORE, Fig. 2) was set up. ${ }^{[18]}$ With this device, a previous combustion system ${ }^{[21]}$ was optimized with regard to the usage of air-tight materials, the reduction of reactor volumes, the purification of carbon dioxide from the oxidation step, and its transfer to evacuated ampoules. $\mathrm{OC}$ is oxidized from the quartz filters at $340{ }^{\circ} \mathrm{C}$ in a stream of pure oxygen during 10 min. ${ }^{[14,22]} \mathrm{EC}$ is oxidized at $650^{\circ} \mathrm{C}$ after complete elimination of OC and interfering water-soluble inorganic compounds, which is done by extraction with diluted hydrochloric acid and water followed by pre-heating in air at $370-390{ }^{\circ} \mathrm{C}$ for $4 \mathrm{~h} . \mathrm{CO}_{2}$ evolving from OC and EC is cryo-trapped and sealed in ampoules for ${ }^{14} \mathrm{C}$ measurement.

In the beginning of ${ }^{14} \mathrm{C}$ analysis more than 50 years ago, only decay counting with gas proportional counting was assessable.[12,23] This technique detects disintegrations of radioactive nuclide so that the efficiency of this process decreases linearly with the extension of the half-life for a given activity and measurement time. On the other hand, mass spectrometric techniques detect radio- 


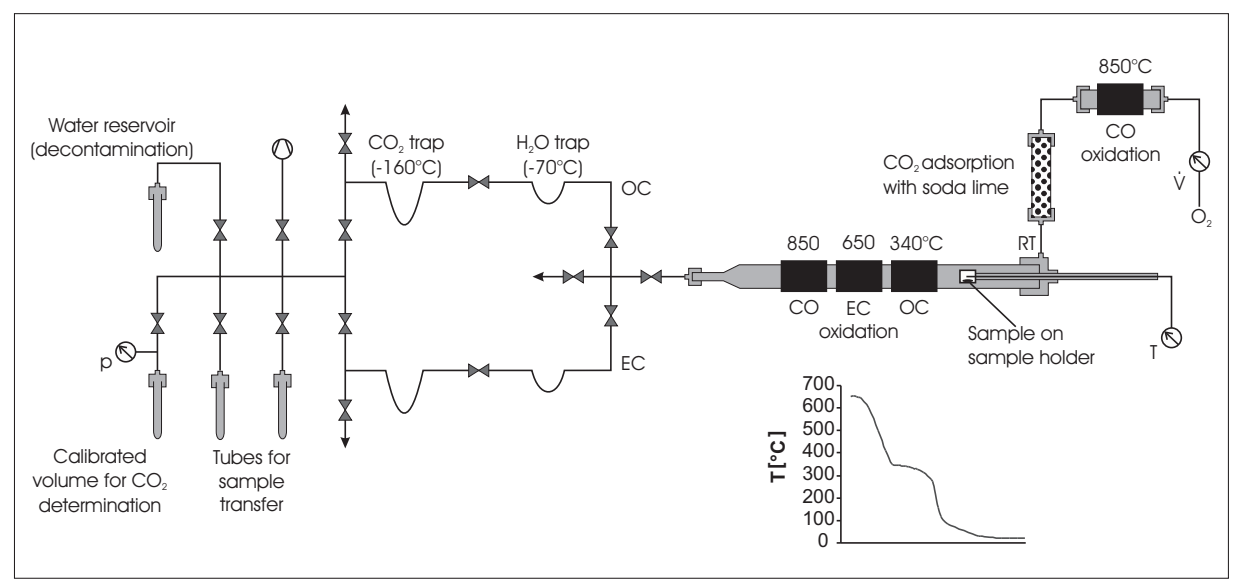

Fig. 2. THEODORE: Two-step heating system for the EC/OC determination of radiocarbon in the environment. ${ }^{[18]}$

active isotopes before decay so that they are favorable especially for long-lived radioisotopes. Consequently, the invention of accelerator mass spectrometry (AMS) enhanced the sensitivity of ${ }^{14} \mathrm{C}$ determination by about three orders of magnitude allowing milligram samples to be analyzed. ${ }^{[23]}$ For aerosol samples, carbon masses of typically $<50 \mu \mathrm{g}$ are available for measurement, which is not achievable for counting techniques and require special methods for analysis of small samples even for AMS. In most AMS laboratories, $\mathrm{CO}_{2}$ from sample preparation is reduced to filamentous carbon for the production of solid measurement targets. ${ }^{[23]}$ This step is crucial for small ${ }^{14} \mathrm{C}$ samples. In early work, we produced solid targets using manganese and cobalt in a sealed ampoule for five days at $640{ }^{\circ} \mathrm{C}$ and $620^{\circ} \mathrm{C}$ for $\mathrm{Mn}$ and Co, respectively. ${ }^{[18,24]}$ This reaction combines the reduction of carbon dioxide with manganese to carbon monoxide and the formation of filamentous carbon on the cobalt surface as a consequence of the Boudouard equilibrium. The solid targets were measured at the compact AMS system at ETH Zurich $^{[25]}$ until 2006. This machine was designed as a small system dedicated for ${ }^{14} \mathrm{C}$ : with a $550 \mathrm{kV}$ pelletron accelerator, total destruction of ${ }^{13} \mathrm{CH}^{+}$and ${ }^{12} \mathrm{CH}_{2}^{+}$interfering molecular ions are performed by multiple collisions in the gas stripper.

\subsection{Technical Developments}

During the first years of work, preparation of solid targets remained the weakest point of ${ }^{14} \mathrm{C}$ analysis of carbonaceous particles even under optimized conditions: for samples containing very low carbon masses or substantial amounts of interfering sulphur-, nitrogen-, or halogen-containing compounds, reaction yields were small, which resulted in large isotopic fractionations ${ }^{[8]}$ or even in total losses of unique samples. ${ }^{[24]}$ These problems were solved with the implementation of a gas ion source ${ }^{[26]}$ in the next generation of small AMS machines: the mini radiocarbon dating system MI-
CADAS ${ }^{[27]}$ became operational in 2005 for ${ }^{14} \mathrm{C}$ measurements in the $1^{+}$charge state. It is a prototype of AMS spectrometers, measurement of $195 \mathrm{kV}$ with a vacuuminsulated high-voltage platform in contrast to previous systems based on conventional particle accelerators. The self-constructed ion source of MICADAS was modified in order to insert gases to the focal point of the sputtering caesium beam. ${ }^{[26]} \mathrm{CO}_{2}$ is released from the sealed ampoules in a cracker, transferred to a syringe, mixed with helium, and fed to the ion source via a glass capillary (Fig. 3). In combination with the uncertain success of solid target production mentioned above, the substantially lower carbon blank contribution (on average $55 \mathrm{ng}$ per analysis compared to $750 \mathrm{ng}$ for gaseous and solid targets, respectively) indicates the superiority of the gaseous ${ }^{14} \mathrm{C}$ measurements. ${ }^{[29]}$

Another advantage of a gas ion source is the potential of on-line coupled systems of separation or combustion of organic compounds. Coupling an elemental analyzer (EA) with AMS generates a multifunctional system, because it provides automated onwhich achieve the terminal voltage for ${ }^{14} \mathrm{C}$ line combustion and ${ }^{14} \mathrm{C}$ measurement of any organic material. ${ }^{[28]}$ Therefore, it can broadly be employed in ${ }^{14} \mathrm{C}$ analysis. The coupling of an EA was realized by extending the existing gas transfer system at the MICADAS ion source (Fig. 3). Carbon dioxide produced in the elemental analyzer is isolated from other combustion gases and focused with two zeolite traps, one internal and one external of the EA. The purified $\mathrm{CO}_{2}$ is transferred from the external trap to the syringe with a low helium flow. The EA introduces a further carbon blank contribution from the tin capsules, in which the samples are combusted. The cleanest capsules analyzed so far contain $340 \mathrm{ng}$. [28]

\section{Source Apportionment of Carbonaceous Aerosols}

\subsection{Interpretation of Results}

As OC and EC often have very different contributions of fossil and non-fossil emissions, ${ }^{[14,15]}{ }^{14} \mathrm{C}$ analysis gains more detailed source information if these fractions are separated from each other compared to ${ }^{14} \mathrm{C}$ measurements of bulk TC. This basic principle was the main motivation for the development of the chemical isolation of OC and EC. As shown in the Table, EC is divided in fossil $\left(\mathrm{EC}_{\mathrm{f}}\right)$ and non-fossil, i.e. wood-burning sources $\left(\mathrm{EC}_{\text {wood }}\right)$. OC is distinguished into fossil $\left(\mathrm{OC}_{\mathrm{f}}\right)$ and non-fossil $\left(\mathrm{OC}_{\mathrm{nf}}\right)$ portions, whereof the latter mainly comprises wood-burning $\left(\mathrm{OC}_{\text {wood }}\right)$ and biogenic $\left(\mathrm{OC}_{\mathrm{bio}}\right)$ emissions. First-order estimations are possible for $\mathrm{OC}_{\text {wood }}$ and $\mathrm{OC}_{\text {bio }}$ by direct interpretation of $\mathrm{OC}_{\mathrm{nf}}$, if one of both sources overwhelms the other. This was performed for the summer campaign at Zurich in 2002, when biogenic SOA was the main non-fossil contribution to $\mathrm{OC},{ }^{[14,32]}$ and for the winter campaigns at Roveredo and Moleno in Southern Switzerland in 2004, which were dominated by emissions from

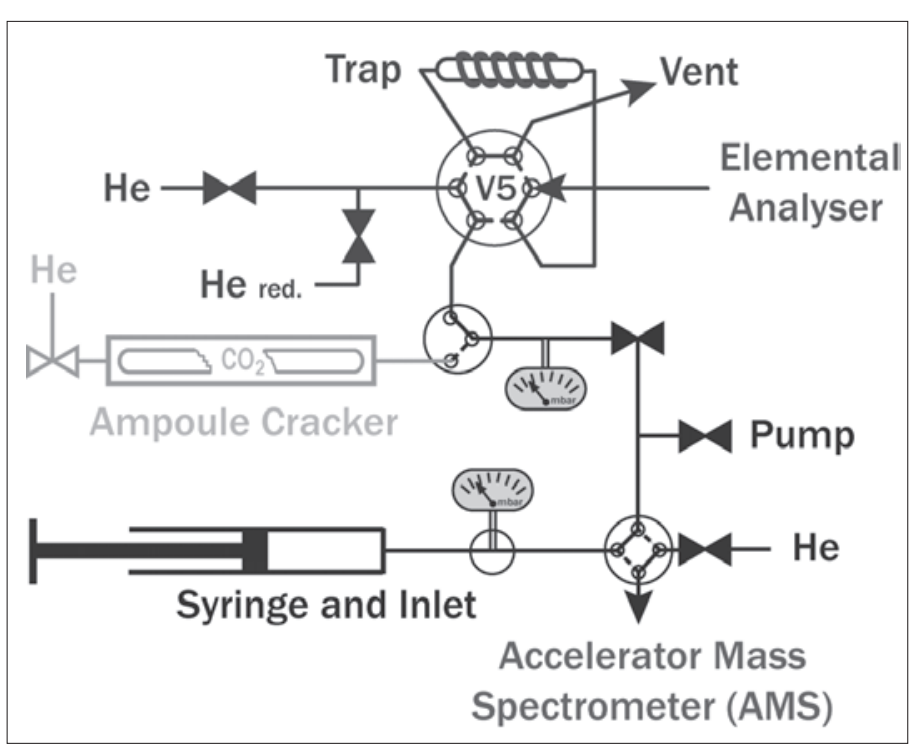

Fig. 3. Scheme of the elemental analyzer/accelerator mass spectrometer (EA-AMS) coupling interface including the EA, the online interface with its external trap (top), the ampoule cracker part (middle), the gas inlet system with pump, pressure sensors and syringe (bottom), and the AMS. ${ }^{[28]}$ 
residential wood combustion. [30] In many other cases, however, both non-fossil OC sources co-occur in comparable amounts so that distinction is desirable. An advanced source apportionment model allows the independent estimation of $\mathrm{OC}_{\text {wood }}$ so that $\mathrm{OC}_{\text {bio }}$ is determined by subtraction of $\mathrm{OC}$ wood from $\mathrm{OC}_{\mathrm{nf}}$. Previously, ${ }^{[15]} \mathrm{EC}_{\text {wood }}$ determinations were used in combination with EC/OC emission ratios for wood burning from the literature. Later, ${ }^{[22]}$ this approach was refined by additional measurements of levoglucosan, a prominent tracer substance of wood burning. [31] This later improvement generates more robust results than the earlier one, as it relies on two independent tracers of $\mathrm{OC}_{\text {wood }}$, namely $\mathrm{EC}_{\text {wood }}$ and levoglucosan. Nevertheless, the division of $\mathrm{OC}_{\mathrm{nf}}$ into OCwood and $\mathrm{OC}_{\text {bio }}$ suffers from large variations of the employed tracer-to-OC emission ratios so that it is only applicable for a certain distribution range of approximately $10 \%$ $<\mathrm{OC}_{\text {bio }} / \mathrm{OC}_{\mathrm{nf}}<70 \%$. As a consequence, the Table presents data of total $\mathrm{OC}_{\mathrm{nf}}$ or distinguished into $\mathrm{OC}_{\text {wood }}$ and $\mathrm{OC}_{\text {bio }}$ according to statistic relevance of the division of $\mathrm{OC}_{\mathrm{nf}}$.

The results from the Table give insight how the source apportionment of carbonaceous particles profits by separated measurements of ${ }^{14} \mathrm{C}$ in EC and OC compared to simple analysis of TC. For the Zurich campaigns in 2002/03 for example, $\mathrm{TC}_{\mathrm{f}}$ fractions are quite similar for all seasons, although emission patterns changed substantially as indicated by the isotopic data of EC and OC.

Main source types, which have been discovered, classified, and/or quantified with this technique, are

- Anthropogenic particle formation from fossil-fuel usage;

- Anthropogenic impacts from residential wood combustion;

- Emissions of biogenic OC with differentiation of biogenic vs. anthropogenic SOA.

\subsection{Fossil-fuel Sources}

The quantification of anthropogenic carbonaceous particles from fossil sources was the motivation for ${ }^{14} \mathrm{C}$ analysis from the beginning. ${ }^{[12]}$ Studies from Los Angeles and Denver in the 1980s and 1990s showed that TC may originate from fossil sources by up to $>70 \%$ in large U.S. cities. ${ }^{[16,17]}$ Zurich and Gothenburg as European urban sites show smaller fossil contributions of $\sim 50 \%,[14,15,22]$ which are only slightly higher than formost of the investigated European rural sites. ${ }^{[22,30,31]}$ During summer, EC is nearly exclusively of fossil origin with soot production from all kinds of diesel engines as the most important source. $[14,15,22]$

\subsection{Wood-burning Contribution}

Theimportance of residential woodburning for winter aerosols in Switzerland was first revealed with ${ }^{14} \mathrm{C}$ for Zurich at a time when emission inventories still underestimated this source. ${ }^{[15]}$ Compared to summer, relative contributions of $\mathrm{EC}_{\text {wood }}$ to $\mathrm{TC}$ were four and two times higher during winter and spring-like weather conditions, respectively (Table). This study initiated further investigations on the relevance of wood burning in Switzerland. During winter smog episodes, when daily average PM10 levels exceeded the legal limit of $50 \mu \mathrm{g} \mathrm{m}^{-3}$ by up to a factor of $3,{ }^{14} \mathrm{C}$ measurements gave evidence for accumulation of local aerosols as the main cause for the high concentrations. ${ }^{[31]}$ The polluted air masses below the strong inversion layers above the Swiss Plateau included substantial portions from residential wood combustion, e.g. $3.5 \mu \mathrm{g} \mathrm{m}^{-3} \mathrm{EC}_{\text {wood }}$ for the rural site Sedel near Lucerne for January/February 2006. At the Alpine valley site Roveredo in Southern Switzerland, wood burning for residential heating was the most dominant source during winter, ${ }^{[30,31]}>50 \%$ of EC and $>80 \%$ of TC originated from local wood-burning emissions in 2004. The low contribution from fossil sources was surprising, because substantial transit traffic from the San Bernardino route passed through the village. Obviously, these emissions were only of minor importance for the high mass of carbonaceous aerosols in Roveredo. The highway site Moleno is also situated in an Alpine valley close to the Gotthard transit route, which carries more traffic than the San Bernardino route. Here, the fossil contribution was more prominent, although even at the this site the wood-burning fraction of TC was $>50 \%$. ${ }^{[30,31]}$

Within the Göte-2005 campaign, particulate matter was analyzed at an urban background site and a rural station in the area of Gothenburg, Sweden. ${ }^{[22]}$ Compared to Zurich, percentage wood-burning contributions were smaller at the urban site, but similar at the rural station during winter. Furthermore, the difference of the wood-burning fraction of EC and OC between the inside and outside of the city was more prominent on the southwest Swedish coast than for the Swiss Plateau. We attributed this effect to the different histories of the air masses entering both regions: At Gothenburg, the local urban impact is better detectable due to the comparatively clean air entering the city. ${ }^{[22]}$ For Zurich, air-masses have accumulated over the moderately populated continent with a rural character so that the local urban emissions play a minor role for the air quality, especially during winter smog episodes. Therefore, the wood-burning contribution measured with ${ }^{14} \mathrm{C}$ in Zurich reflects regional rather than local emissions. This finding indicates - corroborated by the large variations in the Alpine valleys mentioned above - that ${ }^{14} \mathrm{C}$ analyses of carbonaceous aerosols are necessary simultaneously at several stations and for different meteorological conditions to evaluate the distribution of emissions from wood burning over Switzerland properly.

Table. Selected ${ }^{14} \mathrm{C}$ apportionment studies for Switzerland and Sweden presenting fossil and non-fossil sources of OC and EC given as \% of TC. For details see text.

\begin{tabular}{|c|c|c|c|c|c|c|c|c|c|c|c|}
\hline Location & Site & Date & Size & $\begin{array}{l}\mathrm{EC}_{f} \\
{[\%]}\end{array}$ & $\begin{array}{c}\mathrm{EC}_{\text {wood }} \\
{[\%]}\end{array}$ & $\begin{array}{l}\mathrm{OC}_{f} \\
{[\%]}\end{array}$ & $\begin{array}{l}\mathrm{OC}_{\mathrm{nf}} \\
{[\%]}\end{array}$ & $\begin{array}{c}\mathrm{OC}_{\text {wood }} \\
{[\%]}\end{array}$ & $\begin{array}{c}\mathrm{OC}_{\text {bio }} \\
{[\%]}\end{array}$ & $\begin{array}{l}\mathrm{TC}_{f} \\
{[\%]}\end{array}$ & $\begin{array}{c}\text { TC } \\
{\left[\mu \mathrm{g} \mathrm{m}^{-3}\right]}\end{array}$ \\
\hline Zurich, $\mathrm{CH}^{[14,15]}$ & Urban & Aug-Sep 2002 & PM10 & 19 & 1 & 27 & - & 8 & 45 & 46 & 5.9 \\
\hline Zurich, $\mathrm{CH}^{[14,15]}$ & Urban & Feb 2003 & PM10 & 16 & 5 & 25 & - & 31 & 23 & 41 & 19 \\
\hline Zurich, $\mathrm{CH}^{[14,15]}$ & Urban & Mar 2003 & PM10 & 21 & 3 & 23 & - & 17 & 37 & 44 & 6.3 \\
\hline Roveredo (GR), $\mathrm{CH}^{[30,31]}$ & Alpine valley & Jan 2004 & PM10 & 10 & 10 & 8 & 72 & - & - & 17 & 16 \\
\hline Roveredo (GR), $\mathrm{CH}^{[30,31]}$ & Alpine valley & Nov/Dec 2004 & PM1 & 11 & 12 & 4 & 73 & - & - & 15 & 15 \\
\hline Moleno (TI), $\mathrm{CH}^{[30,31]}$ & Highway & Feb 2004 & PM10 & 26 & 4 & 21 & 49 & - & - & 47 & 23 \\
\hline Zurich, $\mathrm{CH}^{[31]}$ & Urban & Jan 2006 & PM1 & 19 & 7 & 20 & 54 & - & - & 39 & 14 \\
\hline Sedel (LU), $\mathrm{CH}^{[31]}$ & Rural & Jan-Feb 2006 & PM10 & 13 & 6 & 24 & 57 & - & - & 37 & 26 \\
\hline Reiden (LU), $\mathrm{CH}^{[31]}$ & Highway & Jan-Feb 2006 & PM10 & 17 & 6 & 22 & 56 & - & - & 39 & 32 \\
\hline Gothenburg, $\mathrm{S}^{[22]}$ & Urban & Feb-Mar 2005 & PM10 & 27 & 3 & 29 & - & 20 & 22 & 56 & 3.0 \\
\hline Råö, S S22] & Rural & Feb 2005 & PM2.5 & 16 & 8 & 28 & - & 31 & 17 & 44 & 1.8 \\
\hline Gothenburg, $\mathrm{S}^{[22]}$ & Urban & Jun-Jul 2006 & PM2.5 & 15 & 1 & 31 & - & 8 & 44 & 47 & 2.7 \\
\hline
\end{tabular}




\subsection{Biogenic Emissions}

High ${ }^{14} \mathrm{C}$ levels during summer indicate the impact of natural aerosol production from primary and secondary biogenic $\mathrm{OC}$ formation. This was revealed from ${ }^{14} \mathrm{C}$ measurements of $\mathrm{OC}$ at the urban background station Zurich, as correlations of $\mathrm{OC}_{\text {bio }}$ with temperature, ozone and biogenic isoprene indicated qualitatively the secondary origin of $\mathrm{OC}_{\text {bio }}{ }^{[32]}$ For episodes of aged aerosols from the same campaign, ${ }^{14} \mathrm{C}$ analysis of the water-soluble portion of OC (WSOC) showed that $94 \%$ of this fraction was nonfossil, ${ }^{[14]}$ which is evidence for the presence of biogenic SOA, as WSOC is enriched with secondary OC. Andreani-Aksoyoglu et al. ${ }^{[33]}$ corrected this data from Zurich for a small contribution from wood burning ${ }^{[15]}$ and suggested that $65-82 \%$ of WSOC originated from biogenic SOA, which compared well with their model predictions of about $80 \%$ biogenic contribution to SOA in Zurich. For winter samples from Zurich, abundance of OC from biogenic sources was unclear due to limited detection capabilities; however, significant amounts of $\mathrm{OC}_{\text {bio }}$ was detected under spring-like conditions. ${ }^{[15]}$ In contrast to that, biogenic SOA was evident in at least one urban sample from Gothenburg also in winter.[22] During an episode in February/March 2005, WSOC showed a nearly exclusively non-fossil origin, whereas substantial contributions from wood burning and cooking could be excluded from ${ }^{14} \mathrm{C}$ measurements of $\mathrm{EC}$ and waterinsoluble OC (WINSOC).

\section{Conclusions}

Airborne carbonaceous aerosols are of increasing environmental interest due to impacts on health and climate. Their emission sources can be attributed to fossil-fuel, biomass-burning and biogenic origins using ${ }^{14} \mathrm{C}$ (radiocarbon) analysis, because fossil materials do not contain this carbon radioisotope in contrast to modern plants. ${ }^{14} \mathrm{C}$ measurements were performed in organic carbon (OC) and elemental carbon (EC), which are two sub-fractions of the carbonaceous aerosol (total carbon, TC). For separation, aerosol filters were thermally treated under oxidizing conditions. OC was isolated by oxidation of the original filters at $340^{\circ} \mathrm{C}$ for $10 \mathrm{~min}$. For EC separation, filters were pretreated by water extraction and precombustion at $370-390{ }^{\circ} \mathrm{C}$ for $4 \mathrm{~h}$, followed by an oxidation at $650{ }^{\circ} \mathrm{C} .{ }^{14} \mathrm{C}$ was measured with compact accelerator mass spectrometry (AMS) devices after preparation of solid targets and directly as carbon dioxide until and later than 2006, respectively. The coupling of the AMS with a gas ion source and an elemental analyzer resulted in simplified and more robust measurement procedures with reduced contaminations compared to
${ }^{14} \mathrm{C}$ analysis using solid targets. As shown for selected studies from Switzerland and Sweden, ${ }^{14} \mathrm{C}$ source apportionment of carbonaceous particles allows classification and quantification of anthropogenic particle formation from fossil-fuel usage, residential wood combustion, and emissions of biogenic OC.

\section{Acknowledgements}

IamgratefultoHeinzW.Gäggeler(University of Bern and PSI), Urs Baltensperger, and André S.H. Prévôt (PSI) for excellent collaboration and intensive discussions as well as Hans-Arno Synal and Lukas Wacker (ETH Zürich) for fruitful cooperation on ${ }^{14} \mathrm{C}$ measurements. The financial support by the Swiss National Science Foundation, the European network ACCENT, the Swiss Federal Office of the Environment, as well as the Swiss Cantons Grisons, Ticino, and Lucerne is acknowledged.

Received: February 2, 2009

[1] U. Baltensperger, S. Nyeki, in, 'Physical and chemical properties of aerosols', Ed. I. Colbeck, Blackie Academic \& Professional, London, 1998, p. 280.

[2] U. Pöschl, Angew. Chem., Int. Ed. 2005, 44, 7520; doi:10.1002/anie.200501122.

[3] P. Forster, V. Ramaswamy, P. Artaxo, T. Berntsen, R. Betts, D. W. Fahey, J. Haywood, J. Lean, D. C. Lowe, G. Myhre, J. Nganga, R. Prinn, G. Raga, M. Schulz, R. van Dorland, in, 'Climate change 2007: the physical science basis, contribution of Working Group I to the Fourth Assessment Report of the Intergovernmental Panel on Climate Change', Ed. S. Solomon, D. Qin, M. Manning, Z. Chen, M. Marquis, K. B. Averyt, M. Tignor, H. L. Miller, Cambridge University Press, Cambridge, 2007

[4] World Health Organization (WHO), 'WHO Air quality guidelines for particulate matter, ozone, nitrogen dioxide and sulfur dioxide, global update 2005, summary of risk assessment', document WHO/SDE/PHE/OEH/06.02, Geneva, 2006.

[5] Swiss Federal Office for the Environment (FOEN), 'Feinstaub PM10, Fragen und Antworten $\mathrm{zu}$ Eigenschaften, Emissionen, Immissionen, Auswirkungen und Massnahmen', Bern, 2006

[6] A. Gelencsér, 'Carbonaceous aerosol', Springer, Dordrecht, 2004.

[7] M. Kalberer, D. Paulsen, M. Sax, M. Steinbacher, J. Dommen, R. Fisseha, E. Weingartner, V. Frankevich, R. Zenobi, U. Baltensperger, Science 2004, 303, 1659.

[8] M. Kanakidou, J. H. Seinfeld, S. N. Pandis, I. Barnes, F. J. Dentener, M. C. Facchini, R. Van Dingenen, B. Ervens, A. Nenes, C. J. Nielsen, E. Swietlicki, J. P. Putaud, Y. Balkanski, S. Fuzzi, J. Horth, G. K. Moortgat, R. Winterhalter, C. E. L. Myhre, K. Tsigaridis, E. Vignati, E. G. Stephanou, J. Wilson, Atmos. Chem. Phys. 2005, 5, 1053.

[9] S. Fuzzi, M. O. Andreae, B. J. Huebert, M. Kulmala, T. C. Bond, M. Boy, S. J. Doherty, A. Guenther, M. Kanakidou, K. Kawamura, V.M. Kerminen, U. Lohmann, L. M. Russell, U. Pöschl, Atmos. Chem. Phys. 2006, 6, 2017.

[10] M. O. Andreae, A. Gelencsér, Atmos. Chem. Phys. 2006, 6, 3131

[11] M. Viana, T. A. J. Kuhlbusch, X. Querol, A. Alastuey, R. M. Harrison, P. K. Hopke, W. Winiwarter, M. Vallius, S. Szidat, A. S. H. Prévôt, C. Hueglin, H. Bloemen, P. Wåhlin, R. Vecchi, A. I. Miranda, A. Kasper-Giebl, W. Maenhaut, R. Hitzenberger, J. Aerosol Sci. 2008, 39, 827; doi:10.1016/j.jaerosci.2008.05.007.
[12] L. A. Currie, Radiocarbon 2000, 42, 115.

[13] S. Szidat, Science 2009, 323, 470

[14] S. Szidat, T. M. Jenk, H. W. Gäggeler, H. A. Synal, R. Fisseha, U. Baltensperger, M. Kalberer, V. Samburova, L. Wacker, M. Saurer M. Schwikowski, I. Hajdas, Radiocarbon 2004 46,475

[15] S. Szidat, T. M. Jenk, H.-A. Synal, M. Kalberer, L. Wacker, I. Hajdas, A. Kasper-Giebl, U. Baltensperger, J. Geophys. Res. 2006, 111, D07206; doi:10.1029/2005JD006590.

[16] L. M. Hildemann, D. B. Klinedinst, G. A Klouda, L. A. Currie, G. R. Cass, Environ. Sci. Technol. 1994, 28, 1565.

[17] D. B. Klinedinst, L. A. Currie, Environ. Sci. Technol. 1999, 33, 4146.

[18] S. Szidat, T. M. Jenk, H. W. Gäggeler, H.-A. Synal, I. Hajdas, G. Bonani, M. Saurer, Nucl. Instr. Meth. Phys. Res. B 2004, 223-224, 829.

[19] S. H. Cadle, P. J. Groblicki, D. P. Stroup, Anal. Chem. 1980, 52, 2201.

[20] H. Cachier, M. P. Bremond, P. Buat-Ménard, Tellus B 1989, 41, 379 .

[21] V. M. H. Lavanchy, H. W. Gäggeler, S. Nyeki, U. Baltensperger, Atmos. Environ. 1999, 33, 2759

[22] S. Szidat, M. Ruff, N. Perron, L. Wacker, H.-A Synal, M. Hallquist, A. S. Shannigrahi, K. E. Yttri, C. Dye, D. Simpson, Atmos. Chem. Phys. 2009, in press.

[23] R. C. Finkel, M. Suter, in, 'Advances in Analytical Geochemistry, Volume 1', Ed. M. W. Rowe, M. Hyman, JAI Press, Greenwich, 1993, p. 1.

[24] T. M. Jenk, S. Szidat, M. Schwikowski, H. W. Gäggeler, L. Wacker, H.-A. Synal, M. Saurer, Nucl. Instr. Meth. Phys. Res. B 2007, 259, 518 ; doi:10.1016/j.nimb2007.01.196.

[25] H.-A. Synal, S. Jacob, M. Suter, Nucl. Instr Meth. Phys. Res. B 2000, 172, 1

[26] M. Ruff, L. Wacker, H. W. Gäggeler, M. Suter, H.-A. Synal, S. Szidat, Radiocarbon 2007, 49 , 307.

[27] H.-A. Synal, M. Stocker, M. Suter, Nucl. Instrum Meth. Phys. Res. B 2007, 259, 7 .

[28] M. Ruff, S. Fahrni, H. W. Gäggeler, I. Hajdas, M. Suter, H.-A. Synal, S. Szidat, L. Wacker, Radiocarbon 2008, submitted.

[29] M. Ruff, H. W. Gäggeler, M. Suter, H.-A. Synal, S. Szidat, L. Wacker, Nucl. Instrum. Meth. Phys. Res. $B$ 2008, submitted.

[30] S. Szidat, A. S. H. Prévôt, J. Sandradewi, M. R. Alfarra, H.-A. Synal, L. Wacker, U. Baltensperger, Geophys. Res. Lett. 2007, 34 L05820; doi:10.1029/2006GL028325.

[31] J. Sandradewi, A. S. H. Prévôt, M. R. Alfarra, S. Szidat, M. N. Wehrli, M. Ruff, S. Weimer, V. A. Lanz, E. Weingartner, N. Perron, A. Caseiro, A. Kasper-Giebl, H. Puxbaum, L. Wacker, U. Baltensperger, Atmos. Chem. Phys. Discuss. 2008, 8, 8091 .

[32] S. Szidat, T. M. Jenk, H. W. Gäggeler, H.-A Synal, R. Fisseha, U. Baltensperger, M. Kalberer V. Samburova, S. Reimann, A. Kasper-Giebl, I. Hajdas, Atmos. Environ. 2004, 38, 4035.

[33] S. Andreani-Aksoyoglu, J. Keller, A. S. H Prévôt, U. Baltensperger, J. Geophys. Res. 2008, 113, D06303; doi:10.1029/2007JD009053. 